\title{
Calculation and Empirical Analysis on the Contributions of R\&D Spending and Patents to China's Economic Growth
}

\author{
Jie Li, Yu Jiang* \\ School of Economics and Management, Southwest Jiaotong University, Chengdu, China \\ Email: 5553501307@qq.com
}

How to cite this paper: Li, J. and Jiang, Y. (2016) Calculation and Empirical Analysis on the Contributions of R\&D Spending and Patents to China's Economic Growth. Theoretical Economics Letters, 6, 1256-1266. http://dx.doi.org/10.4236/tel.2016.66118

Received: October 17, 2016

Accepted: November 25, 2016

Published: November 28, 2016

Copyright $\odot 2016$ by authors and Scientific Research Publishing Inc. This work is licensed under the Creative Commons Attribution International License (CC BY 4.0).

http://creativecommons.org/licenses/by/4.0/ (c) (i) Open Access

\begin{abstract}
Based on the national data from 1995 to 2014, we develop an extended C-D production function model alongside with the Solow growth rate equation to investigate contributions of $\mathrm{R} \& \mathrm{D}$ expenditures and patents to China's GDP respectively. Results indicate that: 1) both $R \& D$ expenditures and patents granted are significantly positive correlated with GDP and the growing output elasticity to GDP is in leaps and bounds after 2000 and $2005 ; 2$ ) comparing to patents granted, R\&D expenditures account for a higher share of contribution to economic growth and the both shares show a fluctuating downward trend; 3 ) the output elasticity of labor is significantly higher than other factors, signaling capital saving technical progress in China. The elasticity coefficient of scientific-technical progress to GDP is small. Nevertheless, its influence is gradually increasing and the intensive economic growth transformation has formed. Some policy implications are distilled after empirical analysis. R\&D application, transformation and related incentive mechanism should be improved. Besides, the fields of R\&D funding should be adjusted to further coordinate the relationship between the structure of $\mathrm{R} \& \mathrm{D}$ expenditures and the industrial structure.
\end{abstract}

\section{Keywords}

R\&D Expenditures, Patents Granted, Contribution Rate to GDP

\section{Introduction}

China's economy has maintained a high growth rate since the reform and opening. Nevertheless, under impacts of international financial crisis and domestic accumulated structural contradictions, China's economic growth rate has begun to decline since 2012, entering into the "new normal" period with economic adjustment. In the situa- 
tion of the "new normal", the Chinese government is committed to adjust the structural contradictions of the economy through innovation-driven and supply-side reform to promote the transformation and upgrading of economic development patterns. It has become the consensus in China's top decision-making and the focus of academic researches that technical innovation is an important support to achieve the anticipated target of the reform. In order to explore the effectiveness and sustainability of R\&D funds and patents, this article studies the contributions of China's R\&D expenditures and patents to GDP respectively, and proposes some pertinent policy implications based on the in-depth analysis of empirical findings.

Adam Smith emphasized the effect of the division of labor on the accumulation of wealth in the "Wealth of Nations". At that time he had a preliminary understanding on the role of technical progress. Solow [1] proposed a model of economic growth referring technical progress, believing that technology, as an independent factor, was exogenous to economic growth. Romer [2] first put forward the concept of technical progress endogenesis, implying that developing countries must put more emphasis on $\mathrm{R} \& \mathrm{D}$ and technical innovation in order to achieve long-term economic growth. G. Cozzi, P.E. Giordani [3] concluded that in equilibrium, a country with less tolerance to ambiguity usually has less R\&D spending, and in the long run, there will be a lag of economic growth compared to a country with more tolerance to ambiguity.

Previous researches in China on relationships between $R \& D$ expenditures, patents and GDP can be summarized as the following:

1) Research on the relationship between $R \& D$ expenditures and economic growth: by using four digit industry data in china, Yanbing $\mathrm{Wu}$ [4] found that there was a significant positive correlation between $\mathrm{R} \& \mathrm{D}$ and productivity. National and provincial production functions were analyzed by Bing Li et al. [5], in which, S\&T input was measured by internal expenditures on S\&T activities. The study shows that the contribution of S\&T investment to China's economic growth is high with the highest output elasticity of S\&T investment going to Beijing on provincial data base. Based on C-D production function, Yuanyuan Liu and Sunhui [6] found that expenditures on $\mathrm{R} \& \mathrm{D}$ were conducive to economic growth in Xinjiang but with significantly less contribution than the national level. Grey correlation analysis by $\mathrm{Li}$ juan Wang and Shida Liu [7] showed that there was a positive relationship between R\&D expenditures and economic growth in Gansu province.

2) Research on the relationship between patents and economic growth: Bojun Fu et al. [8] proved the contribution of technical progress (by patents granted) to economic growth in Inner Mongolia was significant. Zhaofa Zeng et al. [9] found that patents had a significant positive impact on China's economic growth companying with 3 years of lag.

3) The relationship between patents and $R \& D$ expenditures: Zhuqing $\mathrm{Xu}$ [10] believed that $R \& D$ expenditures are an important factor affecting patent output. The enterprise input-output mode is reflected by "R\&D expenditures-patents-market". Jihong Zhang and Yuming $\mathrm{Wu}[11]$ mentioned that $\mathrm{R} \& \mathrm{D}$ expenditures accelerate accumu- 
lation of knowledge and technology, and directly lead to the increase of patent output, which promote economic growth effectively by technology spillover effects and industrial application value. Wen Wang [12] believed that R\&D expenditures promote the creation of new products or upgrading of existing products, improve technical level and efficiency of production processes, and therefore, promote economic growth. The existing researches show that: patent is a part of R\&D expenditures, therefore the impact of R\&D expenditures on economic growth is greater than that of patents.

Existing researches on this field show that scholars are inclined to single factor research, investigating either the relationship between R\&D input and GDP or patents and GDP, proving both R\&D expenditures and patents are conducive to China's economic growth. Meanwhile, the output of the patent, as a part of R\&D expenditures, is affected by $\mathrm{R} \& \mathrm{D}$ expenditures according to related theoretical analysis. This article attempts to combine the two variables to analyze the relationships between them and GDP respectively and compare the contribution to GDP of the two, and tries to put forward pertinent countermeasures.

The reminder of this article proceeds as follows: Section 2 describes the econometric methodology and reports the empirical results. Section 3 concludes and suggests.

\section{Empirical Analysis}

A model is used here to calculate the contributions of R\&D expenditures and patents to GDP respectively.

\subsection{Methodology and Data}

\subsubsection{Model Application}

Extended C-D production function and Solow growth rate model are used to calculate the contribution of independent R\&D to China's GDP. Since the article mainly studies the relationship between GDP and R\&D input, and relationship between GDP and patents respectively, only capital, labor, R\&D spending and patents are included in the production function.

$$
\begin{aligned}
Y & =A K^{\alpha} L^{\beta} R^{\gamma} \\
Y & =A K^{\alpha} L^{\beta} Z^{\omega}
\end{aligned}
$$

where $Y$ represents domestic output; $A$ represents the technical level; $K$ represents capital stock; $L$ represents the labor input; $R$ represents R\&D input; $Z$ represents patents granted; $\alpha, \beta, \gamma$ and $\omega$ represent the output elasticity of capital, labor, R\&D input and patents granted respectively.

Taking logarithm of Equations (1) and (2), and adding random items, we can transform Equations (1) and (2) to:

$$
\begin{aligned}
& \ln Y=\ln A+\alpha \ln K+\beta \ln L+\gamma \ln R+\mu \\
& \ln Y=\ln A+\alpha \ln K+\beta \ln L+\omega \ln Z+\mu
\end{aligned}
$$

Solow growth rate equation is used to calculate the contributions of R\&D input and 
patents to GDP respectively. Equation (3), taken as an example here, is transformed to:

$$
\frac{\Delta Y}{Y}=\frac{\Delta A}{A}+\alpha \frac{\Delta K}{K}+\beta \frac{\Delta L}{L}+\gamma \frac{\Delta R}{R}
$$

or

$$
y=a+\alpha k+\beta l+\gamma r
$$

where $y, k, l$ and $r$ represent the growth rate of $\frac{\Delta Y}{Y}, \frac{\Delta K}{K}, \frac{\Delta L}{L}$ and $\frac{\Delta R}{R}$ respectively. Equation (6) is divided by y:

$$
1=\frac{\alpha k}{y}+\frac{\beta l}{y}+\frac{\gamma r}{y}+\frac{a}{y}
$$

where $E_{K}=\frac{\alpha k}{y}$ represents the contribution rate of capital to GDP; $E_{L}=\frac{\beta l}{y}$ represents the contribution rate of labor to GDP; $E_{R}=\frac{\gamma r}{y}$ represents the contribution rate of R\&D input to GDP; $\frac{a}{y}$ represents the contribution rate of other factors to GDP.

\subsubsection{Data Sources and Interpretation}

The time series data of output, labor input, capital input, $R \& D$ input and patent input from 1995 to 2014 are developed and the output elasticity of all factors are estimated.

GDP is used to measure the domestic output and is transformed to 1995 constant price based on GDP index of each year. Results based on data from "Chinese Statistical Yearbook 2015”, (http://www.stats.gov.cn/tjsj/ndsj/2015/indexch.htm).

Labor input is measured by the difference between the actual labor input and unemployed. Results based on data from Word Bank Data Center, (http://data.worldbank.org.cn/indicator/SL.TLF.TOTL.IN?view=chart) and (http://data.worldbank.org.cn/indicator/SL.UEM.TOTL.ZS?view=chart).

Due to the lags on the economic benefits from capital investment, capital stock calculated by the Perpetual Inventory Method (PIM) is used to measure capital input. The equation is $K_{t}=I_{t}+(1-\sigma) K_{t-1}$, where $K_{t}, K_{t-1}, \sigma$ and $I_{t}$ represent capital stock at time $t$, capital stock at time $t-1$, depreciation rate at time $t$ and capital investment at time $t$ in 1995 constant price respectively. The equation involves four variables: 1) The initial capital stock. The earlier the selected base year, the smaller the influence on each year's estimated capital stock by estimated error of the base period, therefore, 1978 is selected as the base year and estimated capital stock from 1995-2014 are calculated based on the above equation. Similar to Haojie Dan [13], Minjie Dong et al. [14] and many others, this article calculates the initial capital stock through the following equation: Total capital formation in 1978/ (depreciation rate + average growth rate of the actual fixed capital formation in the last 10 years); 2) Investment data. Following Minjie Dong et al. (2013) [14], the gross fixed capital formation is used to measure investment each year; 3) The investment price index. The deflator index in 1995 constant 
price is based on the gross fixed capital formation index from 1978 to 2004 as stated in Hanjie Dan's [13] research. As to the price index from 2005 to 2014, we select the fixed asset investment price index as substitute; 4) The depreciation rate. The same as Haojie Dan [13], this article assumes a depreciation rate of $10.96 \%$. Results based on data from "Chinese Statistical Yearbook 2015",

(http://www.stats.gov.cn/tjsj/ndsj/2015/indexch.htm) and "historical data on the accounting of China's GDP, 1952-2004",

(http://www.yearbookchina.com/naviBooklist-YGNSC-0.html).

R\&D funding includes both capital investment and staff salaries, which can be a better reflector of $R \& D$ input. Therefore, $R \& D$ funding is selected as an index of $R \& D$ input and the CPI deflator is used to get actual expenditures on R\&D in 1995 constant price. Results based on data from “Chinese Statistical Yearbook 2015”, (http://www.stats.gov.cn/tjsj/ndsj/2015/indexch.htm).

The number of patents granted is used to measure R\&D output here. R\&D achievements, namely patents and scientific papers, are the output of R\&D input. When R\&D output of a country is invested as a factor of production, it becomes an indicator of input and represents the level of technological progress of the country. Therefore, as the input elements of technical level, $\mathrm{R} \& \mathrm{D}$ output is considered into the C-D production function. Patents can be commericalized directly as results of application researches and experimental development, implying that using the number of patents granted to measure R\&D output is more objective. Results based on data from "China Statistical Yearbook on S\&T1996-2014"

(http://tongji.cnki.net/kns55/navi/HomePage.aspx?id=N2013010081\&name=YBVCX\&f

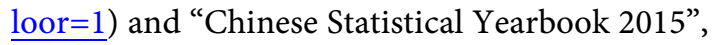
(http://www.stats.gov.cn/tjsj/ndsj/2015/indexch.htm).

\subsection{Empirical Analysis}

The elasticity coefficient of each factor discussed above to economic growth is obtained through regression analysis here, and Solow growth rate equation is used to measure the contributions to GDP from R\&D input and patents respectively.

\subsubsection{Calculation and Analysis of Regression Coefficient}

Eviews8.0 is used to estimate the output elasticity based on Equations (3) and (4). Results from the Chow test show that R\&D input and patents have inflection points in 2000 and 2005, respectively. Dummy variables $D 1$ and $D 2$ are hence introduced to validate. $D 1$ equals to 1 if the time is after 2005 and 0 otherwise; $D 2$ equals to 1 if the time is after 2000 and 0 otherwise. The dummy variable mixture model is established as below:

$$
\begin{aligned}
& \ln Y=\ln A+\alpha \ln K+\beta \ln L+\omega \ln Z+D 1 \times \omega \ln Z+D 1+\mu \\
& \ln Y=\ln A+\alpha \ln K+\beta \ln L+\gamma \ln R+D 2 \times \gamma \ln R+D 2+\mu
\end{aligned}
$$

The model was modified by the ROBUSTLS. $D 1$ is removed according to the regression result of Equation (8), which shows that the coefficients of $D 1$ and constant term 
Table 1. Regression results after adding dummy variables.

\begin{tabular}{cccc}
\hline Independent variables & Formula (8) & Adjusted Formula (8) & Formula (9) \\
\hline $\ln K$ & $0.601161^{* * *}$ & $0.570069^{* * *}$ & $0.363792^{\star * *}$ \\
$\ln L$ & $1.032734^{* * *}$ & $1.377240^{* * *}$ & $0.815957^{* * *}$ \\
$\ln Z$ & $0.034574^{* * *}$ & $0.031097^{* *}$ & -- \\
$D 1 \times \ln Z$ & -0.009127 & $0.005554^{* * *}$ & -- \\
$\ln R$ & -- & -- & $0.211259^{* * *}$ \\
$D 2 \times \ln R$ & -- & -- & $0.041595^{* * *}$ \\
$D 1$ & 0.179034 & -- & -- \\
$D 2$ & -- & -- & $-0.319688^{* * *}$ \\
$C$ & -7.669028 & $-11.09699^{* * *}$ & $-3.404829^{* * *}$ \\
$R^{2}$ & 0.999455 & 0.999439 & 0.999500 \\
\hline
\end{tabular}

Notes: 1) Dependent variable is GDP. 2) ${ }^{* *}$, ** and ${ }^{*}$ indicate the significant level at $1 \%, 5 \%$ and $10 \%$, respectively.

are not significant. The regression results are shown in Table 1.

Table 1 shows that the coefficients of all variables are significant, and the $\mathrm{R}^{2}$ is more than 0.99 , which shows that the goodness of fit of the model is ok. F statistic is significant.

Regression above indicates that all variables have a significant positive correlation with GDP. The highest elasticity coefficient to GDP goes to labor, indicating that technical progress has brought about the substitution of labor for capital with the features of capital-saving. However, the growth rate of employment in China shows a downward trend during the same period, and the dependency ratio of population is on a rise. In 2011, the working-age population of China reached a peak ${ }^{1}$, and China's demographic dividend has faded since then. The previous mechanism of relying on the labor force to drive GDP is difficult to sustain. To achieve economic sustainability, China must rely on the improvement of labor quality in the future, which can also alleviate negative impacts of the demographic dividend reduction.

Both coefficients of R\&D input and patents were small. The output elasticity of patents granted in the period of 1995-2004 was 0.031097, 0.036651 during 2005-2014. The output elasticity of R\&D funding in the period of 1995-1999 was $0.211259,0.252854$ during 2000-2014. The impact of China's R\&D funding and the number of patents granted on the GDP is showing a growth of leaps and bounds, which is highly relevant to China's economic transformation and innovation orientation in the new century. China is gradually transforming to an intensive growth pattern. In General, the elastic coefficient of technological progress in China is still small, which can be explained by: 1) The effect of R\&D input is unsatisfactory with slow updating of $S \& D$ personnel's knowledge and few $R \& D$ achievements $\left.{ }^{2} ; 2\right) R \& D$ funding is dissipated seriously in

1China National Bureau of Statistics. (2013) Statistical bulletin of China's national economic and social development in 2012. http://district.ce.cn/zt/zlk/bg/201302/22/t20130222_24135097_10.shtml

${ }^{2}$ Deng, D.S., Li, L.L., Shi, H., et al. (2015) Investigation Report on the Situation of the Third National Technical Workers.

http://wenku.baidu.com/link?url=EyWPulflL2KSOOQ2CgdqWQCIGi8I3Fso6a4XfLhdpTqkEa_eKICp7WiN 8vFvX4BW_oyVlSjITBZeYbGOfsUJEccjGjDNAcMBCyrCYYmbPyG 
China $^{3}$, and the resource utilization rate is low; 3) Patent conversion rate is low. Zhiqing Shao believes that the current transformation rate of S\&T achievements in China is only about $10 \%^{4}$; 4) Repetitive studies on patents exist.

\subsubsection{Calculation and Analysis of Contribution Rate}

In order to have a more specific analysis of the impact of R\&D input and patents on GDP, respectively, we use the growth rate equation to calculate the contribution rate, and the results are shown in Table 2.

Table 2. Contribution rates of the R\&D input and patents to GDP from 1996 to 2014.

\begin{tabular}{|c|c|c|c|c|c|}
\hline Year & $\begin{array}{l}\text { Growth rate } \\
\text { of GDP }\end{array}$ & $\begin{array}{l}\text { Growth rate of } \\
\text { R\&D input }\end{array}$ & $\begin{array}{l}\text { Contribution } \\
\text { rate of } \mathrm{R} \& \mathrm{D} \\
\text { input }\end{array}$ & $\begin{array}{c}\text { Growth rate } \\
\text { of patents } \\
\text { granted }\end{array}$ & $\begin{array}{l}\text { Contribution rate } \\
\text { of patents granted }\end{array}$ \\
\hline 1996 & $9.925 \%$ & $7.112 \%$ & $15.139 \%$ & $-2.849 \%$ & $-0.893 \%$ \\
\hline 1997 & $9.227 \%$ & $22.458 \%$ & $51.419 \%$ & $16.473 \%$ & $5.552 \%$ \\
\hline 1998 & $7.853 \%$ & $9.101 \%$ & $24.481 \%$ & $33.137 \%$ & $13.121 \%$ \\
\hline 1999 & $7.618 \%$ & $24.944 \%$ & $69.171 \%$ & $47.529 \%$ & $19.401 \%$ \\
\hline 2000 & $8.429 \%$ & $31.403 \%$ & $94.200 \%$ & $5.181 \%$ & $1.911 \%$ \\
\hline 2001 & $8.298 \%$ & $15.575 \%$ & $47.459 \%$ & $8.454 \%$ & $3.168 \%$ \\
\hline 2002 & $9.091 \%$ & $24.506 \%$ & $68.161 \%$ & $15.884 \%$ & $5.434 \%$ \\
\hline 2003 & $10.020 \%$ & $18.154 \%$ & $45.812 \%$ & $37.634 \%$ & $11.680 \%$ \\
\hline 2004 & $10.076 \%$ & $22.922 \%$ & $57.524 \%$ & $4.397 \%$ & $1.357 \%$ \\
\hline 2005 & $11.352 \%$ & $22.404 \%$ & $49.900 \%$ & $12.492 \%$ & $4.033 \%$ \\
\hline 2006 & $12.688 \%$ & $20.757 \%$ & $41.366 \%$ & $25.233 \%$ & $7.289 \%$ \\
\hline 2007 & $14.195 \%$ & $17.892 \%$ & $31.872 \%$ & $31.261 \%$ & $8.071 \%$ \\
\hline 2008 & $9.623 \%$ & $17.479 \%$ & $45.927 \%$ & $17.113 \%$ & $6.518 \%$ \\
\hline 2009 & $9.234 \%$ & $26.580 \%$ & $72.787 \%$ & $41.266 \%$ & $16.380 \%$ \\
\hline 2010 & $10.632 \%$ & $17.841 \%$ & $42.431 \%$ & $40.006 \%$ & $13.791 \%$ \\
\hline 2011 & $9.485 \%$ & $16.694 \%$ & $44.505 \%$ & $17.880 \%$ & $6.909 \%$ \\
\hline 2012 & $7.750 \%$ & $15.547 \%$ & $50.722 \%$ & $30.674 \%$ & $14.506 \%$ \\
\hline 2013 & $7.684 \%$ & $12.117 \%$ & $39.874 \%$ & $4.610 \%$ & $2.199 \%$ \\
\hline 2014 & $7.269 \%$ & $7.712 \%$ & $26.828 \%$ & $-0.785 \%$ & $-0.396 \%$ \\
\hline 1996-1999 & $8.656 \%$ & $15.904 \%$ & $40.052 \%$ & $23.572 \%$ & $9.295 \%$ \\
\hline $2000-2004$ & $9.183 \%$ & $22.512 \%$ & $62.631 \%$ & $14.310 \%$ & $4.710 \%$ \\
\hline 2005-2009 & $11.419 \%$ & $21.023 \%$ & $48.370 \%$ & $25.473 \%$ & $8.458 \%$ \\
\hline 2010-2014 & $8.564 \%$ & $13.982 \%$ & $40.872 \%$ & $18.477 \%$ & $7.402 \%$ \\
\hline $1996-2014$ & $9.497 \%$ & $17.24 \%$ & $48.399 \%$ & $20.294 \%$ & $7.370 \%$ \\
\hline
\end{tabular}

Notes: The data comes from "China Statistical Yearbook on S\&T 1996-2014" and "Chinese Statistical Yearbook 1996-2014".

${ }^{3}$ Ye, C. (2014) S\&R funding: insufficient investment and waste of funds coexist.

http://epaper.chinanews.com/html/2014-03/13/content_45410.htm

${ }^{4}$ Shao, Z.Q. (2015) The transformation rate of scientific and technological achievements in China is only $10 \%$. http://www.aiweibang.com/yuedu/17170473.html 


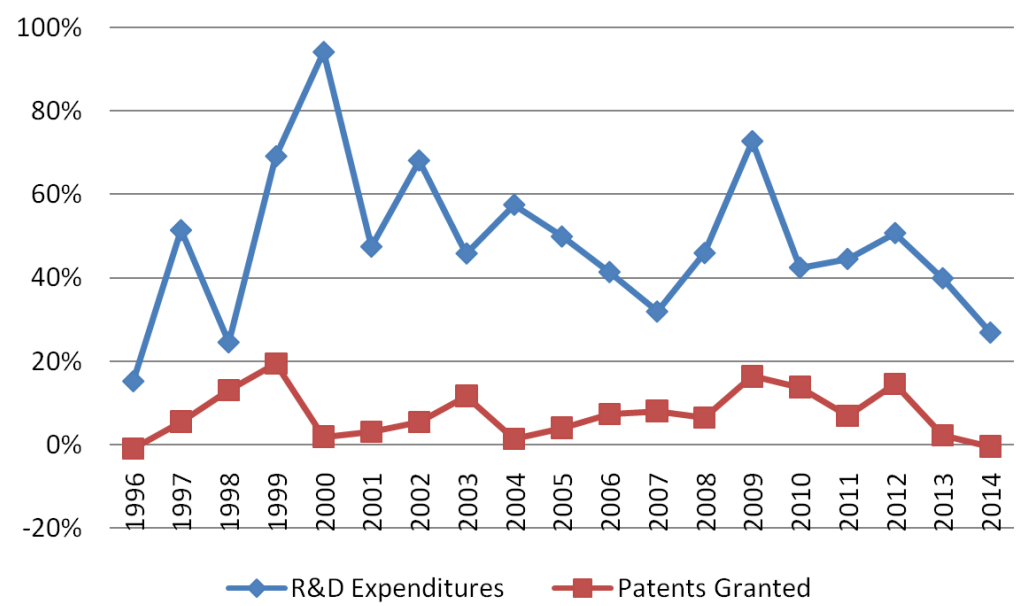

Figure 1. The contribution trends of R\&D input and patents authorized from 1996-2014.

According to Table 2 and Figure 1, we can find:

1) The contribution rate of R\&D input to GDP is greater than the contribution rate of patents granted to GDP, which indicates that patents, as a part of the R\&D process, have a smaller contribution to GDP. From the tendency, the contribution rates of the two to GDP do not show a steady upward trend but with a significant fluctuation characteristic, and there is a downward trend. It is probably because that the growth of the latest S\&T revolution is gradually weakening and the next has not formed yet.

2) The contribution rate of R\&D input to GDP presents a fluctuating downward trend. Three possible explanations are as follows.

First, the growth of R\&D funding is slowing down, which may directly cause the decline in the contribution rate of R\&D input to GDP. According to data above, the contribution rate is in line with a similar fluctuation as the growth rate of R\&D funds.

Second, in the early stage, the output forms of R\&D input are mainly manifested as introduction and imitation of foreign advanced technology, showing a significant effect of late-development advantage. Xibao Guo [15] believed that the rapid development of China's S\&T was mainly due to the introduction and imitation of technology, and the late-development advantage had a diminishing character. Therefore, although the absolute amount of $R \& D$ funds is increasing, the contribution rate of R\&D input to GDP may reduce due to the weakening of the late-development advantage and the increased cost caused by increasing proportion of integrated innovation and independent innovation.

Third, with the diminishment of introduction and direct borrowing of foreign technology, the independent innovation technology does not have obvious and sustained growth. Fundamental research is the source of technological innovation on R\&D funding [16]. However, according to data from 1995 to 2014, the proportion of fundamental research had changed a little with the overall average proportion $5.1 \%$ and the proportion $4.71 \%$ in $2014^{5}$. China's fundamental R\&D input is seriously insufficient.

3) The contribution rate of patents granted to GDP is also small with a trend similar ${ }^{5}$ Data sources: "China Statistical Yearbook on S\&T 1996-2014” and “Chinese Statistical Yearbook 2015”. 
to R\&D input to GDP but has a lag period. The main reasons are stated as follows.

First, the mechanism of transforming technology into real productivity is imperfect. Some patents, especially for those from research institutes and universities, have not been applied. Thus, they do not contribute to GDP growth.

Second, patents from $R \& D$ input have hysteresis quality. Compared to $R \& D$ input, the contribution rate of patents granted to GDP generally lags a few periods. This result is consistent with the researches of Ye Tao, Long Xu [17] and many others, namely that $\mathrm{R} \& \mathrm{D}$ input is beneficial to increasing the number of patents, but there is a certain lag period.

\section{Corresponding Policy Implications}

The empirical analysis shows that both R\&D input and patents have a positive effect on China's GDP, but it also shows a decreasing trend, indicating that the late-development advantage is weakening and the output of independent innovation and its application are insufficient. If this trend cannot be fundamentally reversed, the risk of "the Middle Income Trap" will be increased in China.

Based on the analysis of the empirical results and reasons explained above, four policy implications are distilled:

1) To improve the application transformation mechanism of $R \& D$ output, suggestions here include the following: we should improve the communication mechanism of combining production, learning and researching, focusing on the docking mechanism of learning and researching to production, improve the technical property rights exchange market, strengthen the Government guidance and platform construction, and improve the "Trinity" Function Mechanism of Government Promoting the Guidance, the Service and the Supervision of Application of R\&D Achievements.

2) Incentive mechanism should be improved to enhance the efficiency of $R \& D$ input and patents. The government should strengthen incentives to enterprises' $R \& D$, especially the medium-small-sized enterprises of S\&T, and offset the externalities of technological innovation through tax breaks, financial subsidy, loan guarantee, ex post subsidy and other means [18]. R\&D departments should stimulate the S\&T innovation vitality of research talents through merit pay, career advancement, income from patent property rights and so on.

3) Reform on the field of $R \& D$ funding is necessary. Through government guidance and market mechanism, $\mathrm{R} \& \mathrm{D}$ funds should be invested into fundamental researches and independent innovations to increase technical innovation abilities and to prompt R\&D capital flowing to high-tech enterprises and technology-based SMEs, while curbing $R \& D$ funds flowing to the existing fields of technology imitating, borrowing and simple integrating.

4) Relationship between R\&D input structure and China's Industrial Structure should be coordinated. The structure of R\&D funds should be consistent with the development direction of industrial structure, focusing on fields as dominate industries, 
strategic industries and emerging technical industries.

By exploratory research we have successfully concluded some important results. However, data of patent conversion rate are not available due to a large time span, and more researches are needed to take this factor into consideration.

\section{Acknowledgements}

Financial support from Ministry of Education, P. R. China, Humanities and Social Science Research Planning Foundation (16YJA790020) is gratefully acknowledged.

\section{References}

[1] Solow, R.M. (1956) A Contribution to the Theory of Economic Growth. The Quarterly Journal of Economics, 70, 65-94. http://dx.doi.org/10.2307/1884513

[2] Romer (1990) Endogenous Technological Change. The Journal of Political Economy, 98, 71-102. http://dx.doi.org/10.1086/261725

[3] Cozzi, G. and Giordani, P.E. (2011) Ambiguity Attitude, R\&D Investments and Economic Growth. Journal of Evolutionary Economics, 21, 303-319. http://dx.doi.org/10.1007/s00191-010-0217-x

[4] Wu, Y.B. (2006) R\&D and Productivity: An Empirical Study Based on China's Manufacturing Industry. Economic Research Journal, 11, 60-71.

[5] Li, B., Wang, Z., Li, G.Q. and Chu, Z.P. (2009) An Empirical Study on the Contribution of S\&T Input to Economic Growth in China. Studies in Science of Science, 27, 196-201.

[6] Liu, Y.Y. and Sun, H. (2014) Analysis of the Contribution Rate of S\&T Input to Regional Economic Growth in Xinjiang: Based on Extended C-D Production Function and DEA Method. Science Research Management, 35, 26-32.

[7] Wang, L.J. and Liu, S.D. (2011) Research on the Relationship between S\&T Input and Economic Growth in Gansu Based on Grey Relational Analysis. Science and Technology Management Research, 12, 48-54.

[8] Fu, B.J. and Yang, X.J.L.T. (2014) Analysis of the Effect of Technological Progress on Economic Growth in Inner Mongolia Based on the Solow Model. Science and Technology Management Research, 8, 65-69.

[9] Zeng, Z.F. and Nei, Y.F. (2008) Patent and Economic Growth in China: An Empirical Study. Science and Technology Management Research, 7, 406-407.

[10] Xu, Z.Q. (2004) Patent, Technical Innovation and Economic Growth: Theory and Empirical Analysis. Science and Technology Management Research, 5, 109-111.

[11] Zhang, J.H. and Wu, Y.M. (2007) An Analysis of Dynamic Linkage Mechanism between Patent Output and Regional Economic Growth. Industrial Engineering and Management, 2, 45-50.

[12] Wang, W. (2003) Mechanism Analysis on S\&T Progress to Economic Efficiency Growth. China Soft Science, 2, 96-102.

[13] Dan, H.J. (2008) Re-Estimate of China's Capital Stock: 1952 to 2006. The Journal of Quantitative \& Technical Economics, 10, 17-31.

[14] Dong, M.J. and Liang, Y.M. (2013) The Origin of China's Economic Growth in 1978-2010: A Nonparametric Decomposition Framework. Economic Research Journal, 5, 17-32.

[15] Guo, X.B. (2009) A New Interpretation of the Mystery of China's Rapid Economic Growth: From the Perspective of Late-Development Advantage. Academic Monthly, 41, 63-71. 
[16] Hu, X.J. and Dong, S.R. (2015) Imitation Innovation, Independent Innovation and China's Technical Progress: An Empirical Study and Discussion. Modernization of Management, 1, 67-69.

[17] Tao, Y. and Xu, L. (2007) Research on the Relationship between R\&D Input and Patent Output in China. Science \& Technology Progress and Policy, 24, 7-10.

[18] Liu, N. and Du, Y.P. (2005) A Study on the Incentive Effect of the choice of Government Subsidy Pattern on Enterprise R\&D Innovation. Science \& Technology Progress and Policy, 11, 18-19.

Submit or recommend next manuscript to SCIRP and we will provide best service for you:

Accepting pre-submission inquiries through Email, Facebook, LinkedIn, Twitter, etc. A wide selection of journals (inclusive of 9 subjects, more than 200 journals)

Providing 24-hour high-quality service

User-friendly online submission system

Fair and swift peer-review system

Efficient typesetting and proofreading procedure

Display of the result of downloads and visits, as well as the number of cited articles

Maximum dissemination of your research work

Submit your manuscript at: http://papersubmission.scirp.org/

Or contact tel@scirp.org 